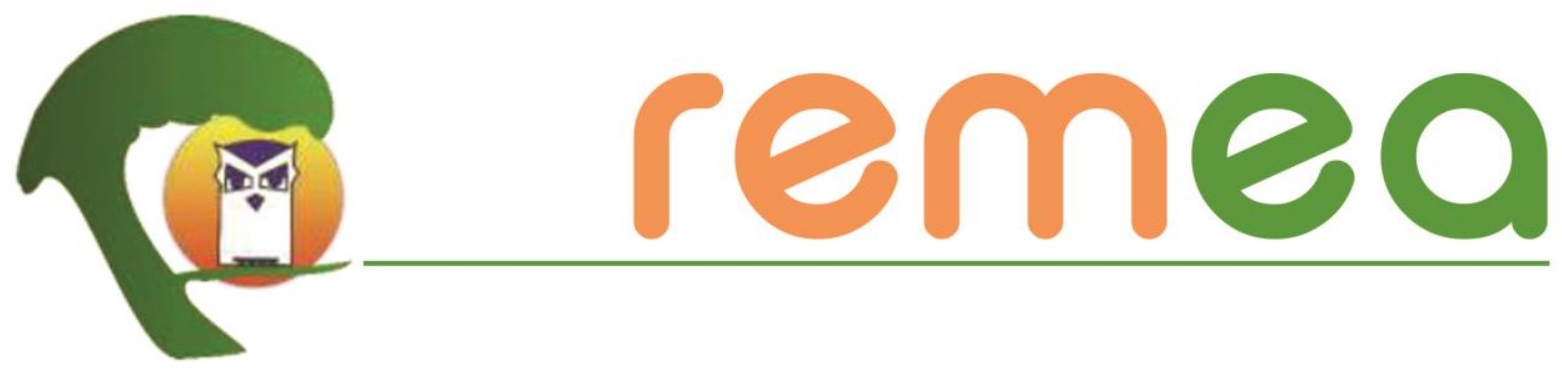

\title{
Índice de educação ambiental para avaliar as múltiplas dimensões socioambientais e de educação ambiental do Programa de Saneamento da Estrada Nova, Belém
}

\author{
Naiara de Almeida Rios ${ }^{1}$ \\ Universidade Federal do Pará \\ ORCID: https://orcid.org/0000-0001-5482-3350 \\ Antônio Cordeiro de Santana² \\ Universidade Federal Rural da Amazônia \\ ORCID: https://orcid.org/0000-0002-4324-9178 \\ Oriana Trindade de Almeida ${ }^{3}$ \\ Universidade Federal do Pará \\ ORCID: https://orcid.org/0000-0002-4254-7982
}

Resumo: O objetivo do artigo foi criar um índice para avaliar a influência da Educação Ambiental (EA), pelo Programa de Saneamento da Estrada Nova (PROMABEN), na vida dos moradores da Bacia Hidrográfica da Estrada Nova, em Belém, de 2006 a 2018. Os resultados foram obtidos, a partir da percepção da população local, por meio da aplicação de questionários semiestruturados. Para o processamento das informações, a Análise Fatorial Exploratória foi utilizada, gerando cinco fatores socioambientais, que explicaram a realidade da bacia e os efeitos da EA. A discussão foi quali-quantitativa, considerando a educação no processo de gestão ambiental. O Índice de Educação Ambiental revelou que o nível de desempenho da EA, pelo programa, foi "baixo" ou "muito baixo", totalizando $68,47 \%$ de baixa significância e de eficiência na vida da população residente.

Palavras-chave: Educação Ambiental; índice de educação ambiental; percepção socioambiental.

\section{Índice de educación ambiental para evaluar las múltiples dimensiones socioambientales y de educación ambiental del Programa de Saneamiento Estrada Nova, Belém}

Resumen: El objetivo del artículo fue crear un índice para evaluar la influencia de la Educación Ambiental (EA) del Programa de Saneamiento Estrada Nova (PROMABEN) en la vida de los habitantes de la Cuenca

\footnotetext{
${ }^{1}$ Doutoranda em Ciências - Desenvolvimento Socioambiental do Programa de Desenvolvimento Sustentável do Trópico Úmido (NAEA/UFPA) e mestre em Planejamento do Desenvolvimento, pela Universidade Federal do Pará. E-mail: naiara-ar@hotmail.com.

2 Doutor em Economia Rural pela Universidade Federal de Viçosa e professor da Universidade Federal Rural da Amazônia (UFRA) e do PPGDSTU - NAEA/UFPA. E-mail: acsufra@gmail.com.

${ }^{3}$ Doutora em Ciências Socioambientais pela University of London e professora adjunta da UFPA no Núcleo de Altos Estudos Amazônicos. E-mail: orianaalmeida@gmail.com.
} 
Hidrográfica Estrada Nova, en Belém, de 2006 a 2018. Los resultados se obtuvieron a partir de la percepción de la población local, mediante la aplicación de cuestionarios semiestructurados. Para el procesamiento de la información, se utilizó el Análisis Factorial Exploratorio, generando cinco factores socioambientales, que explicaron la realidad de la cuenca y los efectos de EA. La discusión fue cualitativa y cuantitativa, considerando la educación en el proceso de gestión ambiental. El Índice de Educación Ambiental reveló que el nivel de desempeño de EA, por parte del programa, fue "bajo" o "muy bajo", totalizando $68.47 \%$ de baja significación y eficiencia en la vida de la población residente.

Palabras clave: Educación Ambiental; índice de educación ambiental; percepción socioambiental.

\section{Environmental education index to assess the multiple socio-environmental and environmental education dimensions of the Estrada Nova Sanitation Program, Belém}

Abstract: The objective of the article was to create an index to assess the influence of Environmental Education (EE) by the Estrada Nova Sanitation Program (PROMABEN) on the lives of residents of the Estrada Nova watershed, in Belém, from 2006 to 2018. The results were obtained from the perception of the local population, through the application of semi-structured questionnaires. For the processing of information, the Exploratory Factor Analysis was used, generating five socio-environmental factors that explained the reality of the basin and the effects of EE. The discussion was qualitative and quantitative, considering education in the environmental management process. The Environmental Education Index revealed that the level of $\mathrm{EE}$ performance by the program was "low" or "very low", totaling $68.47 \%$ of low significance and efficiency in the life of the resident population.

Keywords: Environmental Education; environmental education index; socio-environmental perception.

\section{Introdução}

A Região Norte do Brasil abrange a maior parte da Amazônia, mas 10,2\% da região tem cobertura de esgoto, $17,4 \%$ dos esgotos recebem tratamento e $57,3 \%$ da população tem acesso à água (TRATA BRASIL, 2019). Suas cidades convivem com áreas sem infraestrutura urbana adequada, à mercê das enchentes e dos alagamentos frequentes e da poluição dos recursos hídricos, que se tornaram principal vetor de doenças. As populações de baixa renda são as mais afetadas pelos problemas derivados da pouca infraestrutura de abastecimento de água, de coleta dos resíduos sólidos e de doenças, ligadas à insalubridade e à falta de higiene (SANTANA, 2012; COELHO, 2013; GONÇALVES; GUERRA, 2013; PONTE, 2015; ANELLI, 2015).

Somados aos problemas de infraestrutura urbana, a relação desarmônica entre homem e natureza tem agravado o quadro de degradação socioambiental, resultado dos modelos de utilização e de consumo da sociedade. Restabelecer a harmonia requer uma educação ambiental crítica, alinhada à gestão ambiental, como apontado por Tavares Filho (2007), por Lima (2011), por Rodrigues (2013) e por Leff (2015).

A Educação Ambiental (EA) foi reconhecida internacionalmente, a partir da década de 1970, como elemento estratégico no combate à crise ambiental (LIMA, 2011; LEFF, 2015), 
e passou a compor instrumentos legais, programas e projetos, ligados à promoção da sustentabilidade, propondo transformação no pensamento e nas atitudes, a partir da compreensão da realidade e da participação social (LAYRARGUES, 2000; LEFF, 2015). No entanto, durante sua trajetória, abordagens biologizantes e de caráter conservador, assumidas em várias áreas, reduziram seu propósito (LAYRARGUES, 2000; QUINTAS, 2004; LIMA, 2009; GUIMARÃES, 2013). Logo, a avaliação se tornou, também, um dos itens mais difíceis da EA e, ao mesmo tempo, um dos mais importantes, para que se consiga reunir informações e experiências, a fim de resgatar sua importância e de aproximar ao objetivo inicial (MATTOS; LOUREIRO, 2012).

Avaliar a EA é um dos princípios da Política Nacional de Educação Ambiental (Lei no 9.795/99), e a criação de indicadores ambientais já vem sendo sinalizada, desde a Agenda 21, como uma dessas ferramentas de avaliação e de monitoramento, que atuam, identificando as ações realizadas e detectando falhas ou deficiências cometidas, assim como os sucessos alcançados (ESTEBAN; BENAYAS; GUTIÉRREZ, 2000).

Avançando nas discussões sobre o tema, e devido à complexidade para medir a EA em grandes projetos, este estudo teve, como objetivo, criar um índice para avaliar a influência da Educação Ambiental, pelo Programa de Saneamento da Estrada Nova (PROMABEN), na vida dos moradores da Bacia Hidrográfica da Estrada Nova, em Belém, de 2006 a 2018.

OErro! Indicador não definido. PROMABEN é um programa municipal de saneamento iniciado em 2006, cujo objetivo é de "[...] promoção da melhoria da qualidade de vida da população do Município de Belém, através da recuperação socioambiental e da valorização do meio ambiente urbano" (PMB, p. 2), que envolve um conjunto de obras de infraestrutura. A bacia da Estrada Nova ocupa 16\% da malha urbana de Belém e possui, aproximadamente, 300 mil habitantes, que podem ser beneficiados com o PROMABEN. A EA desenvolvida pelo projeto visa a contribuir com a promoção das sustentabilidades social e institucional, viabilizando a participação efetiva da comunidade, a partir de uma educação ambiental crítica. As ações de EA foram norteadas, a partir do Programa de Educação Ambiental do PROMABEN (PMB, 2007a).

Mais detalhadamente, busca-se entender o grau de atendimento das metas e dos objetivos, no que tange à educação ambiental, e o efeito sobre a qualidade de vida das 
pessoas, com o desenvolvimento da EA e das obras, a partir da percepção da população local. Assim, conhecer e avaliar o grau da percepção ambiental da população se torna também importante, para que se consiga mensurar os seus efeitos e os resultados, em alinhamento com o processo de gestão ambiental do PROMABEN. Neste contexto, qual é o grau de atendimento das metas e dos objetivos do PROMABEN na percepção da população local?

\section{Metodologia}

O estudo adotou metodologias qualitativas e quantitativas para o processamento e para a análise dos resultados, a partir de uma abordagem interdisciplinar, dada a sua importância, destacada por autores como Juntsch (1979), Lattuca (2001) e Ostreng (2010).

Para a coleta de dados, foram utilizadas três fontes: uma base documental, que envolveu o Estudo de Impacto Ambiental (EIA) do PROMABEN (ver PMB, 2007), o Relatório de Impacto Ambiental (RIMA) do PROMABEN (ver PMB, 2007a) e relatórios de obra do PROMABEN e sites da internet do governo municipal de Belém, permitindo o entendimento dos objetivos, das metas e do escopo do projeto. Também foi possível visualizar objetivos e metas, ligados à Educação Ambiental.

Um conjunto de questões abertas foi feito a uma representante do Programa, questionando a implementação, a estrutura, as ações e os resultados da EA, a fim de entender a visão dos implementadores. Também foram aplicados 111 questionários semiestruturados aos moradores da Bacia Hidrográfica da Estrada Nova, para entender a percepção socioambiental deles sobre o PROMABEN e sobre os efeitos da EA.

Para avaliar a educação ambiental, considerou-se a educação no processo de gestão ambiental, que deve: conduzir os habitantes a participarem da vida pública, exercendo a cidadania, promovendo o processo democrático e avaliando o processo de gestão (LAYRARGUES, 2000; PELICIONI, 2004; QUINTAS, 2004), e a compreenderem os modelos de produção e de consumo da sociedade atual, levando em consideração a realidade socioambiental, em que se vive (LOUREIRO, 2015), e a importância dos recursos naturais, como destacado na Conferência de Tbilisi (1977) e na Lei no 9.795/99.

A amostra foi representativa, não censitária, com 95\% de confiança e com erro amostral de $10 \%$. Para cada tema, foi obtida uma questão quantitativa, mas também foram 
obtidas avaliações qualitativas sobre os principais assuntos, sobre a execução das obras, sobre as ações de educação e sobre a comunicação, feita entre o PROMABEN e a Prefeitura, a partir de depoimentos dos moradores. Para a análise dos dados, utilizou-se a análise fatorial exploratória, que gerou cinco fatores, e, a partir dela, foi criado um Índice de Educação Ambiental para a bacia da Estrada Nova.

\section{Análise Fatorial Exploratória}

Análise Fatorial Exploratória (AFE) consiste em um método estatístico multivariado, que avalia as associações entre as variáveis, objetivando resumir ou reduzir as informações das variáveis originais em um conjunto menor de novas variáveis estatísticas, chamadas de fatores, permitindo melhor compreensão da realidade (SANTANA, 2005). Pela sua capacidade de trabalhar com várias variáveis quantitativas e qualitativas, essa técnica tem sido utilizada com sucesso em análises de estudos sociais (SANTANA, 2005; JOHNSON; WICHERN, 2007; SANTANA et al., 2018).

Onze variáveis explicativas foram selecionadas, entre as 31 consideradas relevantes, após análise estatística: Gênero (masculino ou feminino); Educação; Renda; Tempo que mora no bairro; Conhecimento do PROMABEN; como ficou sabendo do PROMABEN; Orientação da Coleta Seletiva do lixo; Qualidade da água, antes do PROMABEN, Qualidade da água com o PROMABEN; Avaliação das mudanças trazidas com o PROMABEN, e Alagamentos, antes do PROMABEN.

Para o processamento de dados, foi utilizado o software SPSS Statistics 18, para aplicar testes de singularidade das matrizes e de adequação da mostra aos métodos estatísticos. O método ortogonal Varimax foi utilizado, para se obter um padrão teoricamente mais significativo e simples de interpretação dos fatores. A especificação básica do modelo de análise fatorial se baseou em Santana (2005), que considerou que cada variável é expressa, em termos dos fatores latentes comuns e de um único fator ou fator específico. A expressão matemática do modelo foi a seguinte (SANTANA, 2005; SANTANA et al., 2018):

$$
X_{i}=\sum_{j=1}^{q} \lambda_{i j} F C_{j}+e_{i}
$$


Em que $X i$ representa as $i$-ésimas variáveis $(i=1,2, \ldots, p) ; \lambda_{i j}$ são os coeficientes, relacionados a cada fator comum ( $i=1, \ldots, p ; j=1, \ldots, q) ; F C_{j}$ são os $j$-ésimos fatores comuns $(\mathrm{j}=1,2, \ldots, \mathrm{q})$; e $e_{i}$ corresponde aos i-ésimos fatores específicos.

Para a viabilidade da adequação de análise fatorial, aplicou-se o Teste de Bartlett, e as correlações foram significantes, ao nível de 0,01, e o teste de Medida Kaiser-Meyer-Olkin (KMO) (SANTANA et al., 2018). As variáveis, associadas a cada fator, puderam ser identificadas, a partir da sua grandeza e da significância de suas cargas fatoriais, ou seja, pertenceu ao fator a variável que obteve maior carga fatorial.

\section{Elaboração do Índice de Educação Ambiental}

Diante dos fatores, foi construído um Índice de Educação Ambiental (IEA), que avaliou o grau de influência da EA desenvolvida pelo PROMABEN. Este, foi dado pela seguinte equação matemática (SANTANA, 2005):

$$
I E A_{i k}=\sum_{j=1}^{q}\left(\frac{\lambda_{j}}{\sum \lambda} F P_{i j k}\right) \quad(i=1, \ldots, N) e(k=I E A)
$$

Em que $\lambda$ é a variância explicada por cada fator, $\Sigma \lambda$ é a soma total da variância, explicada pelo conjunto de fatores comuns, e IEA é o índice na percepção da comunidade.

O escore fatorial foi padronizado $(F P)$ para que os valores fossem todos positivos, e a fórmula utilizada foi a seguinte:

$$
F P_{i}=\left(\frac{F_{i}-F_{\min }}{F_{\max }-F_{\min }}\right) \quad(i=1, \ldots, N)
$$

Em que FP é o escore fatorial padronizado; Fmáx e Fmín são os valores máximo e mínimo, respectivamente, obtidos pelos escores fatoriais, que estão associados aos moradores da Bacia Hidrográfica da Estrada Nova.

Para o IEA, as seguintes variações de intervalo foram utilizadas, conforme orientado por Santana (2005): Valor maior ou igual a 0,7 é considerado alto; valor menor do que 0,7 e igual a 0,5 é considerado médio; valor menor do que 0,5 e igual a 0,3 é considerado baixo; e valor menor do que 0,3 é considerado muito baixo.

\section{A Bacia Hidrográfica da Estrada Nova e o Programa de Educação Ambiental do PROMABEN}

A Bacia Hidrográfica da Estrada Nova (BHEN), localizada na porção sul da cidade de Belém, abrange os bairros Jurunas, Condor, Cremação, Cidade Velha, Batista Campos e 
Guamá. Sua ocupação está diretamente ligada à expansão urbana de Belém e a maioria de seus bairros é considerada periférica, com habitações ao longo dos canais de drenagem ou igarapés, com esgoto sanitário deficitário e com adoção de esgotamento do tipo fossa negra ou, no caso de edificações de palafita, os dejetos são lançados diretamente nos corpos d'água (TRINDADE JÚNIOR, 1993; PMB, 2007).

O Programa de Saneamento da Bacia Hidrográfica da Estrada Nova (PROMABEN) objetiva realizar obras de macrodrenagem e promover a recuperação socioambiental e a valorização do meio ambiente urbano na bacia. $O$ projeto subdividiu a bacia em quatro subbacias (Figura 1) e foram previstos o reassentamento de 269 famílias e a regularização de propriedades. O PROMABEN contempla ações de fortalecimento institucional, de participação comunitária, de comunicação social e de educação ambiental (PMB, 2007). Inicialmente, o programa englobava somente a sub-bacia 1 e, nos anos de 2015, de 2016 e de 2017 as sub-bacias 4, 3 e 2 foram agregadas, respectivamente.

A educação ambiental foi desenvolvida, de acordo com o Programa de Educação Ambiental do PROMABEN, com custo inicial orçado em R\$ 1.445.890,36 (PMB, 2007a), referente à primeira etapa do projeto, na sub-bacia 1 . Sob a perspectiva de participação social, o Programa de Educação Ambiental foi construído, sendo considerados aspectos éticos de comportamento, de cultura, de experiências e de respeito entre os seres humanos e os outros elementos naturais (PMB, 2007a). O projeto apresentado pelos técnicos definiu três etapas para a educação ambiental: informativa, formação de moradores e sustentabilidade. No processo informativo, o programa realizou visitas periódicas e programadas aos moradores, a fim de informá-los sobre coleta do lixo e sobre a importância de não depositar os resíduos em canais ou nas vias. 
Figura 1 - Mapa da Bacia Hidrográfica da Estrada Nova e de suas respectivas sub-bacias, em Belém (PA)

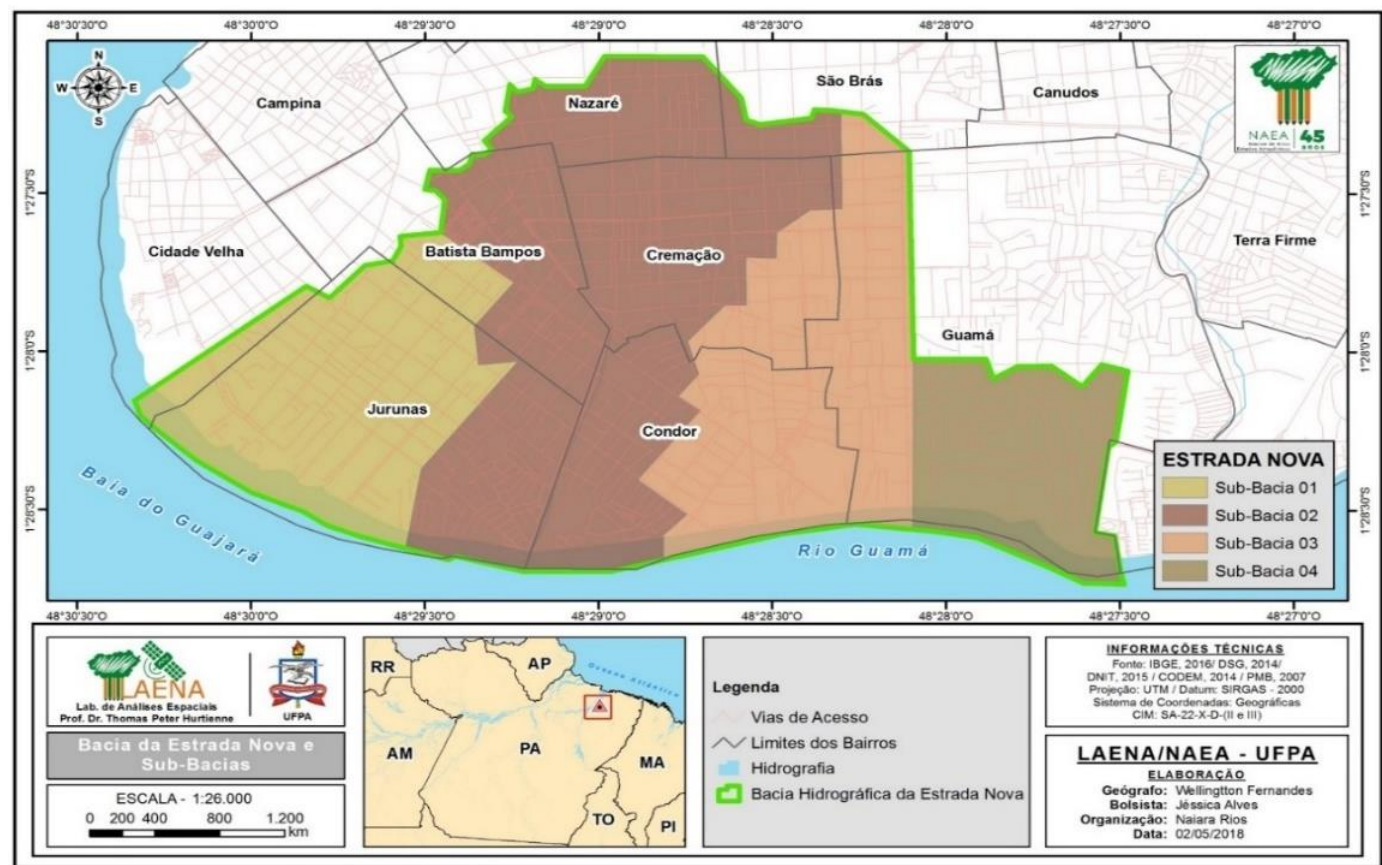

Fonte: Laboratório de Análises Espaciais Prof. Dr. Thomas Peter Hurtienne (LAENA), 2018.

$\mathrm{Na}$ etapa de formação de moradores, aconteceram palestras, oficinas, minicursos e outras ações, com o intuito de capacitar a população para a utilização dos equipamentos de infraestrutura oferecidos pelo programa. Por fim, a etapa sustentabilidade, em que moradores aptos a lidarem com as questões socioambientais ajudaram a manter a infraestrutura trazida pelo PROMABEN, promovendo a sustentabilidade da bacia.

Um conjunto grande de atividades desenvolvidas, relativo à educação ambiental, envolveu: passeios educativos, seminários sobre o ambiente (abordando temas sobre lixo, água, esgotamento sanitário), atividades de arborização, oficinas de reciclagem e de coleta de lixo, atividades de alerta sobre risco de crianças em obras, minicursos para agentes ambientais e para grupos de interesse.

\section{Fatores socioambientais e educação ambiental na Bacia Hidrográfica da Estrada Nova (BHEN)}

A Análise Fatorial Exploratória (AFE) gerou os fatores socioambientais da Bacia Hidrográfica da Estrada Nova, antes e após a implementação do PROMABEN, e estes explicaram o desenvolvimento e a influência da educação ambiental na dinâmica local. A AFE resume o conjunto de informações dispersas em um subconjunto menor de variáveis, os 
fatores, capazes de elucidar o fenômeno estudado, sem perda significativa de informação (SANTANA, 2005; JOHNSON; WICHERN, 2007).

A correlação dos fatores foi identificada na matriz de correlação (Tabela 1), que apresentou correlações significativas e determinante diferente de zero, produzindo uma solução para o modelo fatorial especificado.

Os fatores foram extraídos, a partir da técnica de componentes principais, e obtiveram autovalor maior do que 1. Cinco fatores foram extraídos (Tabela 1) e explicaram 75,41\% da variância total da nuvem de dados, que representa um resultado satisfatório para explicar o fenômeno estudado, pelo critério da variância explicada (SANTANA, 2005). Separadamente, o Fator 1 explicou a maior parcela de variância (23,56\%), o Fator 2 explicou 15,88\%, o Fator 3 explicou 14,17\%, o Fator 4 explicou 11,83\% e o Fator 5 explicou 9,98\% da variância total.

A comunalidade, que representa o grau em que cada variável é explicada pelos cinco componentes, foi superior a 0,64 em todas as ocorrências, enquanto as cargas fatoriais ao quadrado indicaram a importância relativa de cada fator na explicação da variância, que está associada ao conjunto de variáveis analisadas. Todas as cargas fatoriais foram significativas (SANTANA, 2005; SANTANA et al., 2018).

Tabela 1 - Matriz rotacionada varimax de cargas fatoriais do modelo especificado para os moradores da Bacia Hidrográfica da Estrada Nova, em Belém (PA)

\begin{tabular}{|c|c|c|c|c|c|c|}
\hline \multirow[t]{2}{*}{ Variáveis } & \multicolumn{5}{|c|}{ Fatores } & \multirow[t]{2}{*}{ Comunalidade } \\
\hline & 1 & 2 & 3 & 4 & 5 & \\
\hline Educação & 0,847 & 160 & ,061 &,- 100 &,- 186 & 792 \\
\hline Renda & 0,804 & 217 & 123 & 241 & 190 & ,802 \\
\hline $\begin{array}{l}\text { Orientação da Coleta } \\
\text { Seletiva }\end{array}$ & 0,752 & - 150 &,- 055 & ,008 & ,302 & 682 \\
\hline Qualidade da água, antes & 101 & 0,796 & ,090 & ,222 &,- 161 & ,727 \\
\hline Qualidade água, depois & 105 & 0,869 &,- 055 & ,005 & ,079 & ,776 \\
\hline $\begin{array}{l}\text { Avaliação mudanças com } \\
\text { o PROMABEN }\end{array}$ &,- 064 & 0,576 &,- 009 & ,010 & ,552 & ,641 \\
\hline $\begin{array}{l}\text { Conhecimento do } \\
\text { PROMABEN }\end{array}$ &,- 007 & ,052 & 0,875 &,- 041 & 176 & 801 \\
\hline $\begin{array}{l}\text { Como ficou sabendo do } \\
\text { PROMABEN }\end{array}$ & 101 &,- 037 & 0,858 & ,065 &,- 145 & ,773 \\
\hline $\begin{array}{l}\text { Alagamentos, antes do } \\
\text { PROMABEN }\end{array}$ & 146 &,- 026 &,- 164 & 0,844 &,- 069 & ,766 \\
\hline Gênero & ,088 &,- 255 & - ,231 & $-0,788$ & - , 073 & ,753 \\
\hline $\begin{array}{l}\text { Tempo que mora no } \\
\text { bairro }\end{array}$ & 198 &,- 055 & ,034 & - ,012 & 0,860 & ,783 \\
\hline
\end{tabular}




\begin{tabular}{lllllll}
\hline $\begin{array}{l}\text { Soma do quadrado do } \\
\text { autovalor }\end{array}$ & 2,591 & 1,747 & 1,559 & 1,301 & 1,097 & 8,296 \\
\hline Porcentual do traço (\%) & 23,556 & 15,882 & 14,173 & 11,826 & 9,975 & 75,41 \\
\hline Adequação da amostra & \multicolumn{2}{l}{ Teste KMO = 0,570; Teste de Bartlett = 295,737 (p-valor = 0,0000) } \\
\hline
\end{tabular}

Fonte: elaborado pelos autores.

O Fator 1 apresentou três variáveis, que exibiram cargas fatoriais mais altas: Educação, Renda e Orientação sobre Coleta Seletiva (Tabela 1). Esse fator foi nomeado Gestão da Coleta Seletiva.

As variáveis "Educação" e "Renda" representaram elementos socioeconômicos dos moradores entrevistados. A maioria (34\%) tinha escolaridade de ensino médio completo, $8,1 \%$ possuíam nível superior e $21,6 \%$ dos moradores não chegou a completar o ensino fundamental. No quesito "Renda", a maioria (40,5\%) possuía renda familiar de até um salário-mínimo (até $\mathrm{R} \$$ 954) e 30,7\% disseram não ter renda. Essas variáveis, associadas à "Orientação da Coleta Seletiva", sinalizaram que esses aspectos socioeconômicos têm relação com o descarte do lixo e com a maneira, pela qual essas pessoas se relacionam com o meio natural. Ao mesmo tempo, mostra como são necessários a coleta seletiva e o entendimento do descarte correto do lixo na bacia, uma vez que um dos principais problemas socioambientais no local é a grande quantidade de lixo e de entulhos nas vias e nos canais de drenagem, que trazem diversos transtornos para a vida da população.

Segundo o PROMABEN, as principais atividade de EA trataram das questões do lixo e da separação de resíduos, além de firmar parceria com uma cooperativa de catadores de materiais recicláveis, para os moradores, que adotassem a iniciativa. Porém, a maioria dos entrevistados $(77,48 \%)$ disse nunca ter sido orientada sobre a separação correta do lixo ou sobre a coleta seletiva e $78,37 \%$ dos entrevistados observou a inexistência de coleta seletiva na bacia. Adicionalmente, alguns entrevistados desconheciam o significado da expressão "coleta seletiva do lixo".

O Fator 2 foi definido pelas variáveis "Qualidade da água, antes do PROMABEN", "Qualidade da água, depois do PROMABEN", e "Mudanças trazidas pelo PROMABEN" (Tabela 1). Esse fator foi chamado Qualidade da água com o PROMABEN. A associação entre as variáveis desse fator indica que existe um quadro de preocupação e de insatisfação, por parte dos moradores, quanto aos resultados do programa, sobretudo, no que diz respeito à qualidade do abastecimento hídrico. Foram relatadas constantes faltas no abastecimento 
d'água, coloração amarelada e mau odor na água. Ao mesmo tempo, o fator sinaliza como a EA pode promover o diálogo entre a gestão e as necessidades da população, nesse caso, o abastecimento e a qualidade da água.

$\mathrm{Na}$ percepção da população, a água que chegava às residências, antes do PROMABEN, era considerada "péssima" (42,24\%). Com o desenvolvimento do projeto, a qualidade da água ainda é considerada, pela maioria, "péssima" $(27,02 \%)$, "ruim" (27\%) ou "regular" (9\%), totalizando 63,94\% dos entrevistados, porém apresenta algumas melhorias, uma vez que, antes, nenhum dos entrevistados a considerava excelente e, agora, $24,3 \%$ a avaliaram como "boa" ("boa", 34,23\%, e "excelente", 1,8\%), após a implantação do projeto.

Sobre as "mudanças trazidas pelo PROMABEN", a maioria $(63,3 \%)$ não conseguiu identificar quais foram as transformações proporcionadas pelo programa, em relação a vários aspectos, como mobilidade urbana (7\%), segurança (6\%), diminuição de enchentes e de alagamentos (6\%), limpeza de ruas (5\%), outros (15\%). Os entrevistados se mostraram descrentes, quanto aos resultados positivos e ao término do programa, dados os vários prazos de entrega extrapolados. Na avaliação de um morador:

"Com o PROMABEN melhorou a circulação de carros e pessoas, melhorou o saneamento e a segurança também melhorou, porque melhorou o acesso do carro da polícia nas ruas. Mas, o estorvo do não término dessas obras é que é ruim. Tá demorando muito pra acabar." (Informação verbal)

Outra moradora não conseguiu visualizar mudanças satisfatórias com o programa e relatou: "[...] uma obra interminável, muda as linhas de ônibus, muita demora. Mais agilidade por parte da empresa que está à frente das obras" (informação verbal).

Mais um entrevistado avaliou o PROMABEN da seguinte forma: "Uma obra que se fosse como estava projetada, mudaria a vida da população. Porque é relevante, é benéfica pra população. Mas como tá, traz desânimo e transtorno para a população. Indignação por esses gestores irresponsáveis" (Informação verbal).

A insatisfação dos moradores evidencia, também, que a educação ambiental desenvolvida não aproximou a população da gestão. Do contrário, estariam cientes do andamento do projeto e não haveria tantas dúvidas. As visitas aos sistemas de abastecimento de água e de esgoto, bem como a compreensão de seu funcionamento, não configuram participação social e educação ambiental. Aproximar-se da população é ouvir 
suas demandas, suas necessidades e suas avaliações, ao longo da implantação do projeto, para que, assim, ações educacionais sejam conduzidas. Por isso, promover resultados, como a melhoria no abastecimento hídrico, também deve ser prioridade, porque é uma demanda social.

O Fator 3, por sua vez, foi representado pelas variáveis "Conhecimento do PROMABEN" e "Como ficou sabendo do PROMABEN" (Tabela 1) e foi denominado Percepção social do PROMABEN.

O destaque dessas duas variáveis no fator sinalizou que a percepção social sobre a existência de um programa da grandeza do PROMABEN é um importante elemento de avaliação do desempenho da EA, uma vez que esta visa a aproximar o gestor da população, criando elos na comunicação, na participação social e no entendimento da realidade local.

Porém, a maioria dos respondentes mora em um dos bairros da bacia há, pelo menos, dez anos $(92,8 \%)$ e $37,8 \%$ dos entrevistados disseram não conhecer o projeto e, entre aqueles que disseram conhecer $(62,2 \%)$, apenas $17 \%$ relataram ter sido informados pela Prefeitura. O restante dos entrevistados disse ter tido conhecimento por ter visto obras na rua (32\%), pela televisão (5\%), pelas placas sobre a obra $(5 \%)$ ou por outras formas $(18 \%)$. Um morador percebeu o projeto da seguinte maneira: "Não dá nem pra avaliar o programa, porque o projeto ainda não foi concluído. As instituições não vêm aqui, não olham pra cá, não promoveram proximidade com a sociedade. Mas, assim, o entorno aqui piorou com as obras" (informação verbal).

Outro exemplo foi o dos moradores residentes em frente à sede do PROMABEN (na Avenida Bernardo Sayão, no bairro Condor), que observaram nunca ter participado de atividade desenvolvida pelo programa e tampouco sabiam de que a Unidade Coordenadora do PROMABEN se localizava ali. Segundo eles, o único contato feito pela Prefeitura foi referente à desapropriação do imóvel, para o desenvolvimento de obras, tendo sido nesse momento que tiveram conhecimento do projeto.

No Fator 4, as variáveis "Gênero" e "Alagamentos, antes do PROMABEN" (Tabela 1) apresentaram maior significância. A associação entre tais variáveis corresponde à influência dos alagamentos na qualidade de vida da população da bacia, sendo a grande quantidade de lixos e de entulhos nos canais de drenagem um dos principais responsáveis por esse problema. A educação ambiental, por sua vez, é elemento necessário para que a população 
compreenda os ambientes natural e social e a relação com o descarte do seu lixo. Por isso, esse fator foi nomeado Alagamentos e qualidade de vida.

O valor negativo da variável "Gênero" indica efeito inverso no fator, ou seja, a maioria dos entrevistados $(54,05 \%$ do gênero feminino e $45,95 \%$ do gênero masculino) conseguiu perceber os danos e as consequências trazidas pelos alagamentos $(48,65 \%$ disseram que as ruas da bacia alagavam, sempre que chovia; $27,03 \%$ informaram que não alagava; e 24,32\%, que alagava, às vezes). Os alagamentos ainda não diminuíram, mesmo, com alguns trechos das obras de macrodrenagem entregues. De acordo com $50,45 \%$ dos respondentes, os alagamentos acontecem, sempre que chove $(29,73 \%$ disseram que não há alagamento e $19,82 \%$ observaram que estes ocorrem, às vezes).

Outro aspecto é o das vias, que passaram a alagar, a partir das obras. A Rua dos Timbiras (no bairro Jurunas) é um exemplo, que consta no Relatório de Obras do PROMABEN com uma das ruas com obras finalizadas. Outras ruas têm passado pela mesma situação, como a Travessa Bom Jardim, no bairro Jurunas, e a Passagem Santa Fé, no bairro Guamá.

Além disso, a grande quantidade de lixo e de entulho lançada nos canais e nas vias da bacia também não diminuíram e a maior parte dos entrevistados (39\%) considerou os maus hábitos da população, que joga lixos e entulhos nas vias e nos canais, como a principal causa dos alagamentos na bacia ( $10 \%$ não soube responder; $36 \%$ apontaram canais e bueiros entupidos; $11 \%$, canais de drenagem inapropriados; e $4 \%$, outra causa). A representante do PROMABEN reforçou que a educação ambiental feita pelo programa visou a conscientizar a população sobre a forma correta do recolhimento do lixo, informando a importância de não o descartar nas vias e nos canais. Em suas palavras: "[...] A gente gastou, despendeu muito tempo trabalhando a educação ambiental com isso: informativo, informativo, informativo. Bater porta em porta, explicar que o lixo tem que ser colocado no mesmo horário [...]" (informação verbal).

O caráter informativo da campanha sobre o tratamento do lixo, promovida pela educação ambiental, apontado pela representante do PROMABEN, pode ter surtido efeito, junto aos moradores da Rua dos Timbiras, que, após a conclusão das obras de macrodrenagem, compraram camburões e os distribuíram em vários pontos da rua, para que os residentes depositassem o lixo a ser recolhido, e todos os moradores do trecho têm cumprido essa tarefa. Porém, o mesmo não aconteceu em outras vias da bacia, que 
continuam servindo de depósito de lixo e de entulhos. Embora a maioria dos entrevistados consiga compreender que o lixo é descartado de forma inadequada, os instrumentos educacionais citados pela representante do programa não foram suficientes para a adoção de uma nova postura, por parte da população em geral.

Os aspectos citados se somam, ainda, à precariedade no recolhimento do lixo e na limpeza urbana. Segundo os moradores, a coleta do lixo acontece de três a quatro vezes por semana, antes e com o PROMABEN (42,3\%, antes; $46,84 \%$, depois), e, em trechos do bairro Guamá, como a Passagem São Domingos, acontece apenas uma vez por semana, e na Avenida Bernardo Sayão, os moradores não sabem ao certo quando o lixo será recolhido.

Para o Fator 5, a variável "Tempo que mora no bairro" (Tabela 1) teve maior carga fatorial, sendo nomeado Tempo que mora no bairro. Os efeitos positivos e negativos do programa acompanham a trajetória da vivência na bacia, por parte dos entrevistados, que acompanharam o PROMABEN, desde a implementação. Essa variável conseguiu medir os resultados do programa, já que os moradores permaneceram no local, assim como os efeitos da educação ambiental.

\section{Índice de Educação Ambiental na Bacia Hidrográfica da Estrada Nova}

A partir dos resultados apresentados, foi possível criar um Índice de Educação Ambiental para a Bacia Hidrográfica da Estrada Nova, considerando quatro intervalos, que mediram os resultados e que qualificaram o grau de influência da EA na vida dos moradores da bacia. Nessa escala, o valor maior ou igual a 0,7 é considerado alto, o valor menor do que 0,7 e igual a 0,5 foi considerado médio, o valor menor do que 0,5 e igual a 0,3 foi considerado baixo e o valor menor do que 0,3 foi considerado muito baixo (Tabela 2).

Tabela 2 - Índice de educação ambiental na Bacia Hidrográfica da Estrada Nova, em Belém (PA), a partir da percepção da população

\begin{tabular}{cccc} 
Estrato & No de moradores & $\%$ & Qualificação \\
IEA $>=0,7$ & 3 & $2,70 \%$ & Alta \\
$0,5=<\mid \mathrm{EA}<0,7$ & 32 & $28,83 \%$ & Média \\
$0,3=<\mathrm{IEA}<0,5$ & 66 & $59,46 \%$ & Baixa \\
$\mathrm{IEA}<0,3$ & 10 & $9,01 \%$ & Muito Baixa \\
\hline Total & $\mathbf{1 1 1}$ & $\mathbf{1 0 0 \%}$ & - \\
\hline & \multicolumn{2}{c}{ Fonte: elaborado pelos autores. }
\end{tabular}


Para 2,7\% dos entrevistados, a educação ambiental teve efeito alto. Esses moradores representaram a parcela, que possuiu renda familiar superior a nove saláriosmínimos e escolaridade de nível superior. Isso não quer dizer que, para estes, o PROMABEN tenha atuado significativamente, mas mostra que existe uma relação positiva entre o grau de instrução e o Índice de Educação Ambiental e a percepção socioambiental da área. Para 28,83\% dos respondentes, o índice foi considerado de relevância média, significando que as ações do PROMABEN apresentaram algum efeito, proporcionando melhor percepção dos entrevistados sobre aspectos socioambientais, como as questões do lixo e da conservação dos recursos hídricos, e sobre as obras de infraestrutura e sobre a importância da participação social.

Para a maioria dos entrevistados, a educação ambiental do PROMABEN teve baixa significância (59,46\%), não influenciando nas transformações socioambientais necessárias para a mudança de atitudes e para a diminuição da degradação ecossistêmica. Por fim, 9,01\% indicaram que a ação da educação ambiental foi de eficácia muito baixa, significando que a EA não surtiu resultado algum ou não atingiu essas pessoas, direta ou indiretamente.

\section{Os efeitos da educação ambiental do PROMABEN}

Os aspectos identificados em Gestão da Coleta Seletiva e Alagamentos e qualidade de vida retrataram a realidade socioambiental geral da bacia da Estrada Nova. Destaca-se, também, que os problemas do lixo e dos alagamentos foram os temas que nortearam as ações de educação ambiental do PROMABEN, devido às grandes quantidades de lixo, que têm sido um dos maiores problemas socioambientais da bacia, como apontados no EIA do PROMABEN (PMB, 2007).

Porém, na prática, as ações de reciclagem e de coleta seletiva propostas não foram suficientes para que os moradores adotassem a coleta seletiva no dia a dia e para que deixassem de depositar lixos e entulhos nas vias e nos canais. Percebeu-se que as atividades de EA visaram a moldar comportamentos, sem analisar criticamente o modelo de consumo. Isso dificultou o real entendimento dos problemas socioambientais e da importância da reciclagem, por isso tais problemas ainda permanecem. Uma educação ambiental crítica prezaria a mudança de atitudes, a partir da compreensão da realidade e dos deveres ético e cívico, como sinalizaram Layrargues (2000), Quintas (2004), Lima (2011) e Loureiro (2015). 
A EA desenvolvida pelo PROMABEN reproduziu uma visão simplista da realidade, limitando a compreensão da problemática ambiental. Guimarães (2013) denominou esse processo de "armadilha paradigmática". Para romper a "armadilha", é preciso que os elementos da participação social e da reflexão crítica se façam presentes.

Assim, para que a gestão da coleta seletiva seja eficiente e para que o problema do lixo seja solucionado, além dos instrumentos públicos, necessários ao seu estabelecimento, a educação ambiental no local precisa ser contínua e crítica, não se limitando a atividades de reciclagem e de promoção de bons costumes (LAYRARGUES, 2000; LIMA, 2009; LEFF, 2015).

A EA é, também, um processo de educação política, que forma sujeitos e que os prepara para a cidadania ativa e transformadora, contribuindo para a melhoria da qualidade de vida do coletivo (PELICIONI, 2004). Consequentemente, os alagamentos, oriundos da quantidade de lixos e de entulhos nos canais de drenagem e nas vias, diminuirão, pelo entendimento das formas de consumo e de produção de resíduos, o que melhorará a qualidade de vida da população da Estrada Nova.

Aspectos como Qualidade da água com o PROMABEN, Percepção social do PROMABEN e Tempo que mora no bairro corresponderam às dimensões percebidas pelos entrevistados sobre o PROMABEN e sobre as ações de educação ambiental. A inconclusão de obras, o distanciamento da gestão, em relação à população, e a ausência de melhorias no abastecimento hídrico contribuíram com a percepção e com a avaliação negativas do programa, em termos de eficiência.

A percepção negativa sobre a obra pode sinalizar que a EA não assumiu os caráteres democrático e de participação social, dado o desconhecimento dos entrevistados, quanto às ações do programa. A participação popular foi superficial, conservadora e acrítica, uma vez que uma comunidade que caminha para a construção cidadã compreende, de maneira clara, o ambiente em que vive e seu papel social, sendo capaz de avaliar e de participar das políticas públicas, de acordo com Coimbra (2004) e com Pelicioni (2004).

A educação ambiental promovida pelo PROMABEN não trouxe mudanças efetivas à realidade socioambiental complexa e desigual da bacia da Estrada Nova, e perceber e compreender a realidade é um indicador importante de que a educação ambiental tem atingido seus objetivos, sendo esse um ponto alto, também, da gestão ambiental (COIMBRA, 2004; MELAZO, 2005). 
A educação ambiental tem caráteres político e cultural, estando inserida em um contexto que também é histórico. Por esse motivo, os debates sobre educação acompanham, também, os macros debates sociais, que são político-ideológicos (LIMA, 2009). Ou seja, a transformação social e o papel crítico da EA precisam sair do campo burocrático dos planos e dos programas e partir para a ação prática (ALBANI; COUSIN; IBAÑEZ, 2019).

Com os fatores apresentados, foi possível entender que as condições e que a qualidade de vida dos indivíduos evidenciam uma realidade social em construção, dentro de um processo permanente de aprendizado, de intervenção e de participação da sociedade no enfrentamento dos problemas existentes, por isso a educação ambiental é um instrumento importante do processo de gestão que precisa ser priorizada, desenvolvida e avaliada, continuamente, com seriedade e com comprometimento, por parte das políticas públicas, sobretudo, em projetos como o do PROMABEN.

\section{Considerações finais}

Os aspectos da educação ambiental na Bacia Hidrográfica da Estrada Nova, a partir do PROMABEN, foram identificados por cinco fatores socioeconômicos e ambientais, de acordo com a percepção da população local: Gestão da Coleta Seletiva; Qualidade da água com o PROMABEN; Percepção social do PROMABEN; Alagamentos e qualidade de vida; e Tempo que mora no bairro.

Avaliar a EA ainda é um problema complexo, mas a análise fatorial explanatória se mostrou uma técnica promissora. O conjunto de variáveis qualitativas, obtido com base na percepção da sociedade afetada pelo PROMABEM, através da utilização da técnica, pode revelar as dimensões latentes, não conhecidas, que sintetizaram a análise, resumindo o conjunto de informações dispersas em um subconjunto menor de variáveis ou fatores, capazes de explicar o fenômeno estudado, sem perda significativa de informação.

Este tipo de análise permitiu associar as dimensões às situações vivenciadas pela população afetada pelo PROMABEM, como a gestão da coleta e do tratamento do lixo, a qualidade da água, os alagamentos das ruas e das casas, a mudança na qualidade de vida, o que não seria viável, por meio da análise de estatísticas descritivas ou por modelos econométricos tradicionais (SANTANA et al., 2018), mostrando, nesse caso, como a 
percepção da comunidade ajudou a entender o processo de efetivação da educação ambiental na bacia da Estrada Nova e os caminhos percorridos pelo programa, podendo auxiliar nos ajustes necessários.

Com a análise dos fatores, identificaram-se a percepção da população e as expectativas dos moradores, quanto aos resultados do PROMABEN. O programa norteou suas ações de EA, em temáticas, como lixo, recursos hídricos e reciclagem, que são temas válidos, mas, para a eficiência da educação no processo de gestão ambiental, é preciso avançar em práticas permanentes de EA, no estímulo à participação popular e no questionamento ao modelo de consumo. Por isso, os resultados e as transformações socioambientais ainda não foram satisfatórios.

Os resultados do Índice de Educação Ambiental (IEA) revelaram um desempenho entre baixo e muito baixo $(68,47 \%)$, enquanto $28,83 \%$ dos entrevistados avaliaram as ações como de médio desempenho e apenas $2,7 \%$ as estimaram como de alto desempenho. 0 PROMABEN, até essa fase do projeto, não foi capaz de promover transformações significativas na percepção e na atitude dos moradores, quanto às questões socioambientais, a partir do desenvolvimento da educação ambiental.

Portanto, a educação ambiental promovida pelo PROMABEN atingiu a população da bacia de forma diferente, tendo sido insuficiente para promover transformações na realidade socioambiental do espaço ou para estimular a participação social no processo de gestão.

Com base na realidade apresentada, ratifica-se que a educação ambiental deve estar presente em todas as etapas da gestão ambiental, para que a Política Nacional de Educação Ambiental cumpra o seu papel.

A educação ambiental não é a solução para todos os problemas ambientais, mas uma ferramenta, que contribui para a construção de novos pensamentos e atitudes, promovendo um nexo entre aprendizagem e conhecimento, capacitando os indivíduos a entenderem o mundo de forma crítica e, ao mesmo tempo, a serem protagonistas no espaço social.

\section{Referências}

ANELLI, Renato Luiz Sobral. Uma nova cidade para as águas urbanas. Estudos Avançados, v. 
29, n. 84, p. 69-84. São Paulo, maio/ago. 2015. Disponível em: https://doi: 10.1590/S010340142015000200005. Acesso em: 08 jan. 2020.

BRASIL. Lei no 9.795 de abril de 1999. Política Nacional de Educação Ambiental. Diário Oficial [da] República Federativa do Brasil, Brasília, 27 de abr. 1999. Disponível em: http://www.planalto.gov.br/ccivil 03/leis/l9795.htm. Acesso em: 13 jul. 2020.

COELHO, Maria Célia Nunes. Impactos ambientais em áreas urbanas: Teorias, conceitos e métodos de pesquisa. In: GUERRA, Antônio José Teixeira; CUNHA, Sanda Batista da (Org.). Impactos ambientais urbanos no Brasil. 10. ed. Rio de Janeiro: Bertrand Brasil, 2013. p. 1946.

COIMBRA, José de Ávila Aguiar. Linguagem e percepção ambiental. In: PHILIPPI JR, Arlindo; ROMÉRO, Marcelo de Andrade; BRUNA, Gilda Collet (ed.). Curso de Gestão Ambiental. Barueri: Manole, 2004. p. 525-570.

ESTEBAN, Gema de; BENAYAS, Javier; GUTIÉRREZ, José. La utilización de indicadores de desarrollo de la educación ambiental como instrumentos para la evaluación de políticas de educación ambiental. Tópicos en Educación Ambiental, v. 2, n. 4, p. 61-72, 2000.

GUIMARÃES, Mauro. Por uma educação ambiental crítica na sociedade atual. Revista Margens Interdisciplinar, v. 7, n. 9, 2013. Disponível em: https://doi:10.18542/rmi.v7i9.2767. Acesso em: 20 fev. 2020.

JACOBI, Pedro. Educação ambiental, cidadania e sustentabilidade. Cadernos de Pesquisa, v. 118, p. 189-206, 2003. Disponível em: https://doi: 10.1590/S0100-15742003000100008. Acesso em: 10 jan. 2020.

JOHNSON, R. A.; WICHERN, D. W. Applied multivariate statistical analysis. New Jersey: Prentice-Hall, 2007.

LATTUCA, Lisa R. Considering interdisciplinarity. In: LATTUCA, Lisa R. Creating interdiciplinarity: interdisciplinary research and teaching among college and university faculty. 1. ed. [S.I.]: Vanderbilt University Press, 2001. p. 1-22.

LAYRARGUES, Philippe Pomier. Educação para a gestão ambiental: a cidadania no enfrentamento político dos conflitos socioambientais. In: LOUREIRO, Carlos Frederico Bernardo; LAYRARGUES, Philippe Pomier; CASTRO, Ronaldo Souza de (Org.). Sociedade e meio ambiente: a educação ambiental em debate. São Paulo: Cortez, 2000.

LEFF, Enrique. Saber ambiental: Sustentabilidade, racionalidade, complexidade, poder. Tradução de Lúcia Mathilde Endlich Orth. 11. ed. Petrópolis: Vozes, 2015.

LIMA, Gustavo Ferreira da Costa. Educação ambiental crítica: Do socioambientalismo às sociedades sustentáveis. Educação e Pesquisa, v. 35, n. 1, p. 145-163, 2009. Disponível em: https://doi: 10.1590/S1517-97022009000100010. Acesso em: 19 mar. 2020. 
LIMA, Gustavo Ferreira da Costa. Educação ambiental no Brasil: Formação, identidades e desafios. Campinas: Papirus, 2011.

LOUREIRO, Carlos Frederico B. Educação Ambiental e Epistemologia Crítica. REMEA - Revista Eletrônica Do Mestrado Em Educação Ambiental, v. 32, n. 2, p. 159-176, 2015. Disponível em: https://doi.org/10.14295/remea.v32i2.5536. Acesso em: 10 jul. 2021.

Mapa da Bacia Hidrográfica da Estrada Nova e suas respectivas sub-bacias, Belém/PA. Belém: Laboratório de Análises Espaciais Prof. Dr. Thomas Peter Hurtienne (LAENA), 2018. 1 mapa, color. Escala 1:26.000.

MATTOS, Luiza Maria Abreu de; LOUREIRO, Carlos Frederico Bernardo. Avaliação em educação ambiental: estudo de caso de um projeto em contexto de licenciamento. Pesquisa em Educação Ambiental, v. 6, n. 2, p. 33-43, 2012. Disponível em: https://doi: 10.18675/2177-580X.vol6.n2.p33-43. Acesso em: 09 maio 2020.

MELAZO, Guilherme Coelho. Percepção ambiental e educação ambiental: uma reflexão sobre as relações interpessoais. Olhares e trilhas, ano VI, v. 6, p. 45-51, 2005. Disponível em: https://doi.org/10.14393/OT. Acesso em: 04 dez. 2020.

OSTRENG, Willi. Science without boundaries: Interdisciplinarity in Research, Society and Politics. [S.I.]: University Press of America Inc., 2010.

PELICIONI, Maria Cecília Focesi. Fundamentos da Educação Ambiental. In: PHILIPPI JR, Arlindo; ROMÉRO, Marcelo de Andrade; BRUNA, Gilda Collet (Org.). Curso de Gestão Ambiental. Barueri: Manole, 2004. p. 459-483.

BELÉM (município). Prefeitura Municipal de Belém (PMB). Estudo de Impacto Ambiental (EIA): Processo de Licenciamento ambiental da Bacia Hidrográfica da Estrada Nova. Programa de reabilitação urbano-ambiental da Bacia Hidrográfica da Estrada Nova (PROMABEN). Memorial descritivo: Tomo 01/03. Prefeitura de Belém. Belém: Engesolo Engenharia LTDA, 2007.

BELÉM (município). Prefeitura Municipal de Belém (PMB). Relatório de Impacto Ambiental (RIMA): Processo de Licenciamento ambiental da Bacia Hidrográfica da Estrada Nova. Programa de reabilitação urbana e ambiental da Bacia Hidrográfica da Estrada Nova (PROMABEN). Memorial descritivo: Tomo 01/02. Prefeitura de Belém. Belém: Engesolo Engenharia LTDA, set. 2007a.

PONTE, Juliano Pamplona Ximenes. Belém do Pará: cidade e água. Cadernos Metrópole, v. 17, n. 33, p. 41-60, 2015. Disponível em: https://doi: 10.1590/2236-9996.2015-3302. Acesso em: 08 jul. 2020.

PONTE, Juliano Pamplona Ximenes; RODRIGUES, Roberta Menezes; LEÃO, Monique Bentes Machado Sardo; PINHEIRO, Andréa de Cássia Lopes. A macrodrenagem da Bacia Hidrográfica 
da Estrada Nova, Belém-PA. In: MARX, Vanessa; COSTA, Marco Aurélio (org.). Participação, conflitos e intervenções urbanas: contribuições ao Habitat III. Porto Alegre: Editora da UFRGS/CEGOV, 2016. p. 74-98.

QUINTAS, José Silva. Educação no processo de gestão ambiental: uma proposta de educação ambiental transformadora e emancipatória. In: LAYRARGUES, Phillipe Pomier (Org.).

Identidades da educação ambiental brasileira. Brasília: Ministério do Meio Ambiente -

Diretoria de Educação Ambiental, 2004. p. 113-140.

SANTANA, Antônio Cordeiro de. Elementos de economia, agronegócio e desenvolvimento local. Belém: GTZ; TDU; UFRA, 2005. 197 p.

SANTANA, Antônio Cordeiro de; SANTANA, Ádina Lima de; OLIVEIRA, Gilmara Maureline Teles da Silva de; SANTANA, Ádamo Lima de; QUARESMA, Javan Lobato. A importância dos serviços ecossistêmicos para o desenvolvimento econômico e o bem-estar social na percepção da população: o caso da floresta nacional de Carajás. Nativa, v. 6, p. 689-698, 2018. Disponível em: https://periodicoscientificos.ufmt.br/ojs/index.php/nativa Larticle/view/6418. Acesso em: 28 jun. 2020.

SANTANA, Joana Valente. Pequenas cidades na Amazônia: desigualdade e seletividade no investimento da infraestrutura habitacional. In: SANTANA, Joana Valente; HOLANDA, Anna Carolina Gomes; MOURA, Aldebaran de Socorro Farias de (Org.) A questão da habitação em municípios periurbanos na Amazônia. Belém: Ed. UFPA, 2012. p. 77-94.

TAVARES FILHO, Thomé Eliziário. Educação ambiental e qualidade de vida na favela.

Dialógica - Revista Eletrônica da FACED, v. 1, n. 3, 2007. Disponível em:

http://dialogica.ufam.edu.br/dialogican3.htm. Acesso em: 28 jan. 2020.

TRATA BRASIL. Dia da Amazônia - saiba a situação dos 8 estados da região. 2019. Disponível em: http://www.tratabrasil.org.br/blog/2019/09/05/dia-da-amazonia-saiba-a-situacao-dos8-estados-da-regiao/. Acesso em: 29 jan. 2020.

TRINDADE JÚNIOR, Saint-Clair Cordeiro da. Produção do espaço e diversidade do uso do solo em área de baixada saneada - Belém (PA). 1993. Dissertação (Mestrado em Planejamento do Desenvolvimento) - NAEA, Universidade Federal do Pará, Belém, 1993.

Submetido em: 18-12-2020.

Publicado em: 20-08-2021. 